\title{
OPHTHALMIC SERVICES IN THE BERKS., BUCKS. AND OXFORD REGION
}

A report of the sub-committee appointed by the Medical Advisory Committee of the Berks., Bucks. and Oxon. Regional Hospitals Council to survey and report upon the ophthalmic services and orthoptic clinics in the region was submitted to the Medical Advisory Committee at the end of last year.

The report is in three sections; the first contains a summary of existing ophthalnic services, the second gives an outline of a regional ophthalmic service and the last deals with recommendations.

In part 1 the facts are grouped under 1.--Regional and Key Hospitals. 2.-Intermediate Hospitals. 3.-Other Hospitals. 4.-Ophthalmic surgeons in active practice or visiting (v.): 5.Ophthalmic medical practitioners in the region who are on the list of the National Ophthalmic Treatment Board. 6.-Dispensing opticians. 7.-Access to special apparatus. 8.-Facilities for consultation with other departments. 9.-Teaching centres.

Summarising sections 4 and 5 we note $(a)$ that there are 14 ophthalmic surgeons normally engaged in active practice and on hospital staffs in the region; $(b)$ there are 6 ophthalmic surgeons normally engaged in practice who are not attached to hospitals in the region. There are 27 ophthalmic medical practitioners in the National Ophthalmic Treatment Board list (allowing for duplication of names); of these 7 are included in $(a)$ and 2 are included in $(b)$ : the net number of ophthalmic medical personnel is therefore 38 .

With regard to Dispensing Opticians the Oxford Eye Hospital has no arrangements for dispensing prescriptions, patients may go to any optician they choose and the hospital has no control or supervision over the results. The Royal Berkshire Hospital has arrangements with both Dispensing and with sight-testing opticians; the King Edward VII Hospital, Windsor, has arrangements with a dispensing optician, but patients are free to go elsewhere, and the Royal Bucks. Hospital Aylesbury, has recently contracted with dispensing opticians. The opticians at Banbury are on the N.O.T.B. list of Díspensing opticians, but do not limit themselves to dispensing.

All key hospitals in the region have access to special-apparatus, though the Royal Bucks. Hospital, Aylesbury, sends "Magnet" cases to London.

$\therefore$ Undergraduate and Post-graduate ophthalmic teaching is carried out at the Oxford Eye Hospital, but at no other hospital in the region. 'Here also nurses may obtain the ophthalmic certificate. There are orthoptic schools at the Oxford and Royal Berkshire Hospitals.

Part II outlines the facilities which should be provided in a fully integrated regional ophthalmic service. They are :-(1) consultation 
by appointment with an ophthalmic surgeon, for all categories of patients, as near as possible to their homes. (2) In-patient and outpatient treatment for all categories of patients in properly equipped hospitals. (3) School refraction clinics in suitably equipped premises, preferably organised through the Regional centre and held in the O. P. Department of hospitals. (4) Orthoptic treatment clinics in association with school refraction clinics. (5) Special apparatus, e.g., magnet, short-wave treatment, operative diathermy, $\mathrm{X}$-ray, ultra-violet light and slit-lamps at all key hospitals. Bacteriological and pathological facilities. (7) Facilities for consultation with other departments and for dental treatment. Accurately dispensed spectacles at reasonable prices. (9) Facilities for fitting and supplying artificial eyes, contact glasses, etc. (10) Facilities for certification of blindness. (11) Trained almoners at all key hospitals and other hospitals where possible, adequate liaison with the National Institute for the Blind, and facilities for education of partially sighted or blind children and adults. (12) A University centre for undergraduate and post-graduate study, in which could be held scientific meetings and meetings for discussion of ophthalmic matters concerning the region. (13) Facilities' for restarch, both at the regional centre and elsewhere in the region. (14) A training school for ophthalmic nurses. (15) A training school for orthoptists.

In Part III the sub-committee recommends that the ophthalmic services of the region should be re-organized and extended on a regional basis. There should be a regional ophthalmic centre at Oxford (the Oxford Eye Hospital) closely linked with the ophthalmic units at the key hospitals at Reading, Windsor and Aylesbury; the development of existing ophthalmic units (or the creation of new ones) at the intermediate hospitals at Banbury, Newbury, Maidenhead and High Wycombe; and the establishment of subsidiary O. P. clinics at some or all of the cottage hospitals.

The Oxford Eye Hospital is admirably adapted to -act as the regional centre. The key hospitals at Reading, Windsor and Aylesbury are general hospitals with ophthalmic departments (including beds) staffed by their own hon. ophthalmic surgeons. Reading has an orthoptic school and some facilities for research.

The ophthalmic departments at the intermediate hospitals should be under the control of the hospitals concerned and staffed either by their ophthalmic surgeons or by visiting staff from the regional or key hospitals. They should be linked to theìr appropriate key hospital for purposes of consultation, access to special departments and apparatus, etc.

The subsidiary clinics at the cottage hospitals should be adequately equipped and linked to their appropriate key hospitals. They should be available to local ophthalmic medical practitioners on the list of the

- N.O.T.B. . . . and such men or women should be encouraged to act as clinical assistants to the regional or key hospitals. Ideally every 
doctor practising ophthalmology in the region should be attached to a hospital. . . . Other paragraphs deal with appointments : categories of patients; school refraction clinics; orthoptics; dispensing of spectacles, etc. 'It is noted that present arrangements' with regard to the dispensing of spectacles are far from satisfactory, and an ideal solution would be the setting up of a regional organisation which could supply all spectacles and employ its own dispensers and fitters. In this way control could be exercised over the accuracy and quality of the spectacles provided, as well as the prices charged. There would seem to be some need for the establishment of myope schools or sight-saving classes in local schools. And facilities for bacteriological examinations in the remoter districts are capable of improvement. The report ends with a diagram showing the type of organisation recommended and a list of the number of beds needed. At present there are 35 beds available at Oxford, 70 are required. At Reading there are 21 and 50 are required. At Windsor there are 9 and 40 are required, and at Aylesbury there are no specially allocated eye beds and 20 are needed. And besides these a few beds would be required at each of the four intermediate hospitals.

The Committee is to be congratulated on an important and painstaking review of the subject.

\section{ABSTRACTS}

\section{MISCELLÁNEOUS}

(1) Le Marquand, H. S. and Recordon, E. G. (R.A.M.C.).Aseptic cavernous sinus thrombosis with recovery. Lancet, 246, p. 247, 1944.

(1) Le Marquand and Recordon describe the case of a male, aged 29 years, who developed bilateral cavernous sinus thrombosis 13 days after a hard blow on the right eye with a soccer ball. Commotio retinae and a pre-retinal haemorrhage over the juxtapapillary course of the superior temporal vessels were noted after the injury.

Radiographs did not show a fracture of the skull, but the authors comment that injury to the sphenoid bone could not be excluded. All investigations, including cerebro-spinal. fluid, urine and blood examinations were negative. It seems likely that trauma gave rise. to an aseptic clot in either the superior or inferior ophthalmic vein, and that this spread to the right cavernous sinus. In two weeks the patient recovered fully. Some residual retinal disturbance was present in the right eye, the visual acuity of which became $6 / 6$ partly.

H. B. Stallard. 